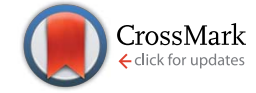

Cite this: J. Mater. Chem. A, 2016, 4, 1855

Received 22nd November 2015 Accepted 3rd January 2016

DOI: $10.1039 / c 5 \operatorname{ta} 09483 f$

www.rsc.org/MaterialsA

\section{Effect of side chain length on the charge transport, morphology, and photovoltaic performance of conjugated polymers in bulk heterojunction solar cells $\dagger$}

Chunhui Duan, ${ }^{a}$ Robin E. M. Willems, ${ }^{a}$ Jacobus J. van Franeker, ${ }^{\text {ab }}$ Bardo J. Bruijnaers, ${ }^{a}$ Martijn M. Wienk ${ }^{\text {ac }}$ and René A. J. Janssen ${ }^{\star a c}$

\begin{abstract}
The effect of side chain length on the photovoltaic properties of conjugated polymers is systematically investigated with two sets of polymers that bear different alkyl side chain lengths based on benzodithiophene and benzo[2,1,3]thiadiazole or 5,6-difluorobenzo[2,1,3]thiadiazole. Characterization of the photovoltaic cells reveals a strong interdependency between the side chain length of conjugated polymers and photovoltaic performances (power conversion efficiency, short-circuit current, and fill factor) of the resulting bulk-heterojunction (BHJ) solar cells. Charge carrier transport and external quantum efficiency (EQE) measurements in combination with morphology characterization suggest that too long side chains lead to deteriorated charge transport, suboptimal $\mathrm{BHJ}$ morphology, considerable bimolecular recombination, and consequently poor photovoltaic performances. On the other hand, when the side chains are too short, they cannot afford a high enough solubility and molecular weight for the resulting polymers and produce poor solar cell performance as well. This study shows that side chain optimization is of significant importance to maximize the potential of photovoltaic active conjugated polymers, which indicates the fruitful molecular design rules toward highly efficient $\mathrm{BHJ}$ polymer solar cells.
\end{abstract}

\section{Introduction}

Polymer solar cells (PSCs) have received considerable attention in the past decade in the prospect of producing highly efficient, large-area, flexible photovoltaic modules via cheap roll-to-roll processing. ${ }^{1,2}$ Extensive research into bulk-heterojunction $(\mathrm{BHJ})$ solar cells with photoactive layers composed of a conjugated polymer as the electron donor and a fullerene derivative as the electron acceptor has resulted in tremendous progress, with power conversion efficiencies (PCEs) exceeding 10\% in singlejunction devices. ${ }^{3-8}$ These achievements were largely driven by the development of new materials, especially state-of-the-art photoactive semiconducting conjugated polymers. ${ }^{\mathbf{4 , 8 - 1 2}}$ Based on a fundamental understanding of the film microstructure ${ }^{13-17}$ and device physics, ${ }^{18-22}$ it has been possible to correlate the chemical structure of these novel materials with the device performance and thereby promote further advances in materials

${ }^{a}$ Molecular Materials and Nanosystems, Institute for Complex Molecular Systems, Eindhoven University of Technology, P. O. Box 513, 5600 MB Eindhoven, The Netherlands. E-mail: r.a.j.janssen@tue.nl

${ }^{b}$ Dutch Polymer Institute (DPI), P.O. Box 902, 5600 AX Eindhoven, The Netherlands ${ }^{c}$ Dutch Institute for Fundamental Energy Research, De Zaale 20, 5612 AJ Eindhoven, The Netherlands

$\dagger$ Electronic supplementary information (ESI) available: Additional graphs and tables. See DOI: 10.1039/c5ta09483f development and solar cell efficiencies. To pursue state-of-the-art new materials and to establish structure-property relationships, chemists have been manipulating the backbone structures of conjugated polymers. ${ }^{23-30}$ Implementing alternating donoracceptor chain motifs, ${ }^{31,32}$ creating new heteroaromatic building blocks, ${ }^{33-36}$ and developing a reliable synthetic machinery for introducing heteroatoms (e.g. fluorine and sulfur) $)^{37,38}$ and functionalities (e.g. imide, acyl, and carboxylate groups) $)^{39-41}$ into the conjugated backbone have proved to be effective methods to create novel materials with improved performance.

Recently, side chains of conjugated polymers are found to play a key role in polymer packing, backbone orientation, and BHJ morphology, in addition to serving primarily as solubilizing groups. ${ }^{\mathbf{4 2 - 4 4}}$ The reported results show that the type, shape, bulkiness, length, position, and branching point of side chains all exert important effects on the intrinsic physical properties of neat polymers, on the microstructure of $\mathrm{BHJ}$ films, and even on the interaction between the polymers and fullerene acceptor. ${ }^{4-58}$ For instance, it was found that shifting the alkyl chain branching point away from the conjugated backbone in diketopyrrolopyrrole polymers can improve the hole mobility and enhance the short-circuit current density $\left(J_{\mathrm{sc}}\right)$ and PCE because of improved polymer crystallinity. ${ }^{49}$ Osaka et al. ${ }^{54}$ demonstrated that the backbone orientation of polymers with respect to the substrate can be tuned by altering the alkyl side 
chain composition. Wang's group ${ }^{55}$ compared two pairs of indacenodithiophene-based polymers with meta-hexylphenyl or para-hexylphenyl side chains on the indacenodithiophene unit and found that the meta-substituted polymers offer superior photovoltaic performances.

Despite these discoveries, it is still very difficult to draw simple and unambiguous correlations between a change in the side chain structure and an observed variation in device performance. Generally, subtle changes such as variation in molecular weight and processing history can lead to significant difference in both the film microstructure and device performance, making the establishment of a reliable structureproperty relationship highly challenging. Moreover, most reported structure-property correlations have been established on the basis of a specific polymer system and necessarily a limited number of derivatives are studied. This limits the universality of the design rules. As making a decision on the length of side chains is a frequently encountered issue in the design of new polymers for chemists, we attempt in this contribution to establish a reliable and universal relationship

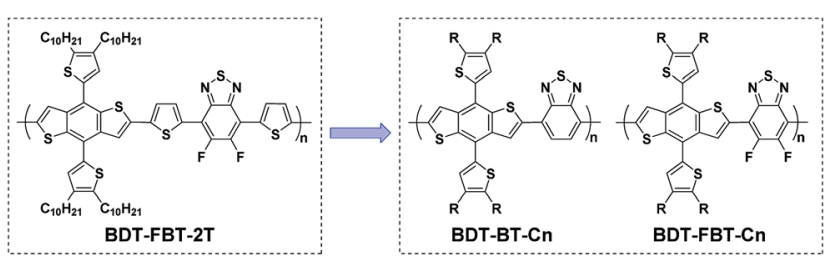

Scheme 1 Molecular design rationales of BDT-BT-Cn and BDT-FBTCn polymers. between the side chain length of conjugated polymers and the photovoltaic performance by systematically investigating various factors that determine the final device performances of PSCs with a large number of polymers that belong to two different material systems.

Recently, we created a wide band gap donor-acceptor polymer, BDT-FBT-2T, based on benzo[1,2- $\left.b: 4,5-b^{\prime}\right]$ dithiophene (BDT) and 5,6-difluorobenzo[2,1,3]thiadiazole (FBT) toward multi-junction PSC applications. ${ }^{59}$ A shortcoming of BDT-FBT$2 \mathrm{~T}$ is the relatively low open-circuit voltage $\left(V_{\mathrm{oc}}\right)$ compared to the optical band gap $\left(E_{\mathrm{g}}\right)$ in single-junction PSCs. To solve this problem, a feasible method is removing the electron-rich thiophene rings from the conjugated backbone of BDT-FBT-2T (Scheme 1) to downshift the highest occupied molecular orbital (HOMO) energy level while keeping $E_{\mathrm{g}}$ unchanged. Two structurally related polymer systems, BDT-BT-C $n$ and BDT-FBT-Cn, thus emerge and were chosen for correlating the relationship between the side chain length and photovoltaic performance in this paper. Three polymers (BDT-BT-C40, BDT-BT-C32, and BDT-BT-C24) in the BDT-BT-Cn system and five polymers (BDTFBT-C40, BDT-FBT-C32, BDT-FBT-C24, BDT-FBT-C20, and BDTFBT-C16) in the BDT-FBT-Cn system were synthesized. The chemical structures of the polymers are shown in Scheme 2. The "Cn" in the abbreviations of the polymers denotes the statistical average number of carbon atoms in alkyl side chains of each repeat unit. Our results show that there are unambiguous trends between the length of side chains and photovoltaic properties of the polymers. The length of the side chains determines the photovoltaic properties of the polymers by influencing charge carrier transport and recombination, as well

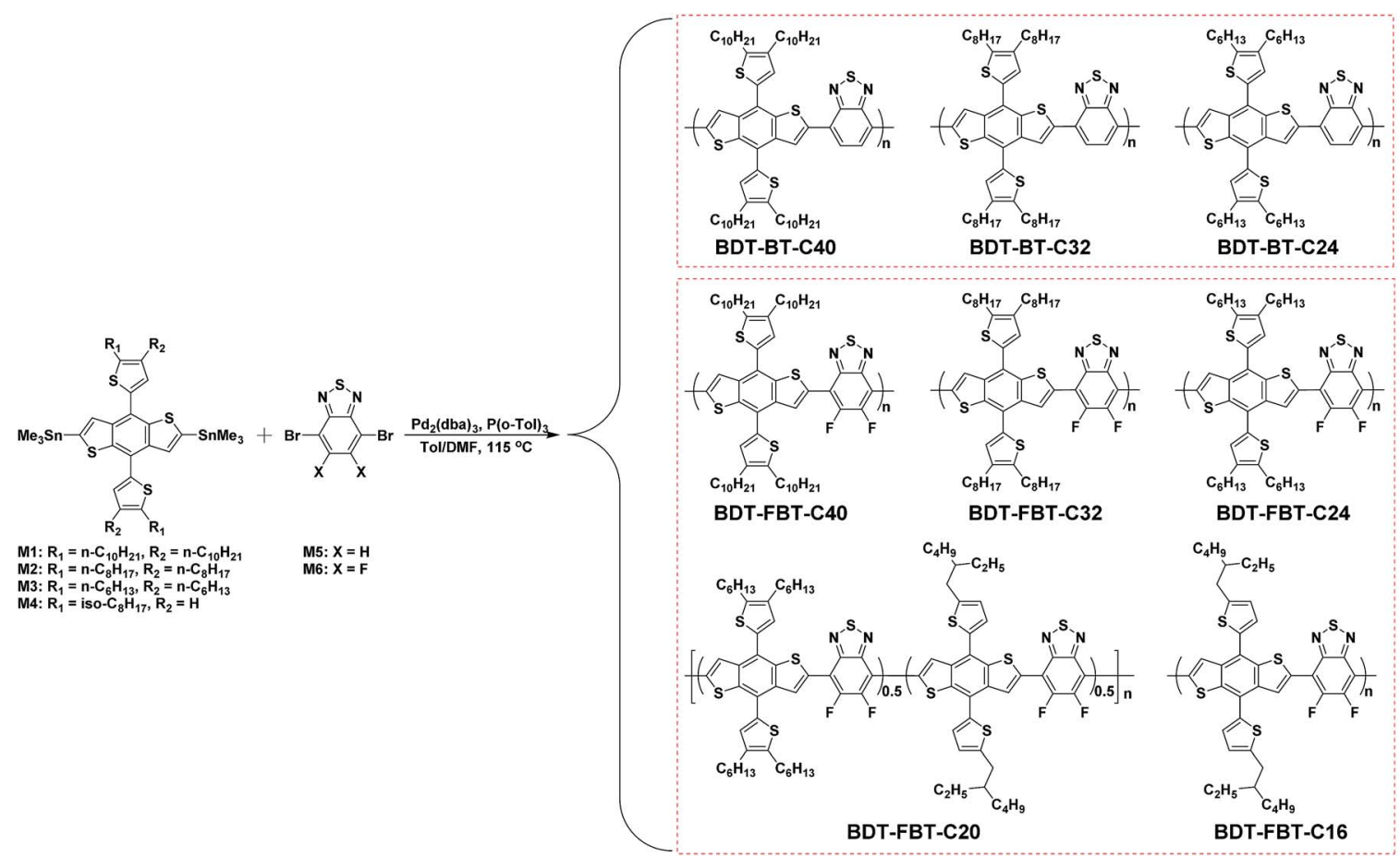

Scheme 2 The synthesis route to BDT-BT-C40, BDT-BT-C32, BDT-BT-C24, BDT-FBT-C40, BDT-FBT-C32, BDT-FBT-C24, BDT-FBT-C20, and BDT-FBT-C16. 
as $\mathrm{BHJ}$ morphology. Noticeably, during the course of this work, the research group in the University of Melbourne reported two structurally relevant polymers which belong to the polymer systems of BDT-BT-Cn and BDT-FBT-Cn, respectively, but featuring different alkyl side chains. ${ }^{60,61}$ The maximum PCE of the single-junction PSCs based on one of their polymers reached $9.4 \%$. It is worth pointing out that the " $\mathrm{Cn}$ " of their state-of-theart polymers is close to the optimal value observed in our polymer systems, which strongly validates our correlations.

\section{Results and discussion}

\subsection{Molecular design and synthesis}

To methodically investigate the effects of side chain length on photovoltaic properties of polymers in PSCs, "Cn" is systematically varied in the two polymer systems, BDT-BT-Cn and BDTFBT-Cn, by using different BDT monomers in the polymerization. The polymers of BDT-BT-C40, BDT-BT-C32, and BDT-BT$\mathrm{C} 24$ were synthesized for the BDT-BT-Cn system, and the polymers of BDT-FBT-C40, BDT-FBT-C32, BDT-FBT-C24, BDT-FBTC20, and BDT-FBT-C16 were synthesized for the BDT-FBT-Cn system. Among these polymers, BDT-FBT-C16 is insoluble in any solvent and was thus not characterized further. "C20" in BDT-FBT-C20 denotes the statistical average value of the number of alkyl chain carbon atoms in each repeat unit of the polymer due to the random copolymerization. The chemical structures and synthetic scheme of the polymers are illustrated in Scheme 2. The polymers were synthesized by the Stille crosscoupling reaction with different bis(trimethyltin)-BDT monomers and dibrominated benzo[2,1,3]thiadiazole (BT) or FBT monomers. To properly establish structure-property relationships and make a fair comparison of a set of polymers, similar molecular weights are required.62 For example, different conclusions with respect to the effect of fluorination on solar cell performance were drawn for structurally similar polymers when their molecular weights differed. ${ }^{63-65}$ Gel permeation chromatography (GPC) measurements, performed at $140{ }^{\circ} \mathrm{C}$ using ortho-dichlorobenzene (o-DCB) as the eluent to reduce aggregation of polymer chains, show that good control of the polymerization reaction was achieved and similar molecular weights were obtained for the useful polymers, except for BDTFBT-C20 (Table 1 and Fig. S1, ESI $\dagger$ ). The low molecular weight of
BDT-FBT-C20 is attributed to the lack of sufficient side chains, impeding the growth of polymer chains during polymerization. All the other useful polymers possess similar number-average molecular weights $\left(M_{\mathrm{n}}\right)$ of $30-40 \mathrm{~kg} \mathrm{~mol}{ }^{-1}$ with similar polydispersity (PDI). All useful polymers are readily soluble in chlorinated aromatic solvents such as chlorobenzene (CB) and $o$-DCB.

\subsection{Optical properties and energy levels}

UV-vis absorption spectra of the polymers in thin films are shown in Fig. 1 and relevant data are summarized in Table 1. The UV-vis absorption spectra in dilute solutions are presented in Fig. S2 (ESI $\dagger$ ). All BDT-BT-C $n$ and BDT-FBT-Cn polymers exhibit similar absorption maxima $\left(\lambda_{\max } \approx 665 \mathrm{~nm}\right)$ in solution and in thin films $\left(\lambda_{\max } \approx 670 \mathrm{~nm}\right)$. The main difference is the stronger absorption at $\sim 490 \mathrm{~nm}$ of the BDT-FBT-C $n$ polymers compared to the BDT-BT-Cn polymers. In thin films, all polymers show an absorption onset between 720 and $730 \mathrm{~nm}$, corresponding to an $E_{\mathrm{g}}$ of $\sim 1.7 \mathrm{eV}$, which is close to the ideal value for wide band gap absorbers toward multi-junction PSC applications. ${ }^{59}$ In the normalized absorption spectrum of BDT-FBT$\mathrm{C} 20$, the intensity of the vibronic peak at $\sim 600 \mathrm{~nm}$ is substantially larger than those of the other BDT-FBT-Cn polymers. The normalized absorption spectra of the three other BDT-FBT-Cn polymers overlap each other almost completely. The small deviation of the absorption spectrum of BDT-FBT-C20 with respect to other BDT-FBT-Cn polymers may be caused by its low molecular weight and less ordered side chain pattern. Almost complete overlap of normalized absorption spectra is also observed for the three BDT-BT-C $n$ polymers. These similarities indicate that the effective conjugation length has been achieved and that the side chain length has little influence on the optical properties of the polymers.

The HOMO and lowest unoccupied molecular orbital (LUMO) energy levels of the polymers were determined by cyclic voltammetry (CV) experiments and are referenced to a work function of ferrocene of $-5.23 \mathrm{eV}$, used as the internal standard (Fig. 2, Table 1, and Fig. S3, ESI $\dagger$ ). The HOMO and LUMO levels of the BDT-FBT-Cn polymers are slightly deeper in energy than those of the BDT-BT-Cn polymers as a result of the electronwithdrawing effect of the fluorine atoms. The exception is BDT-

Table 1 Molecular weights, optical properties, and energy levels of BDT-BT-C40, BDT-BT-C32, BDT-BT-C24, BDT-FBT-C40, BDT-FBT-C32, BDT-FBT-C24, and BDT-FBT-C20

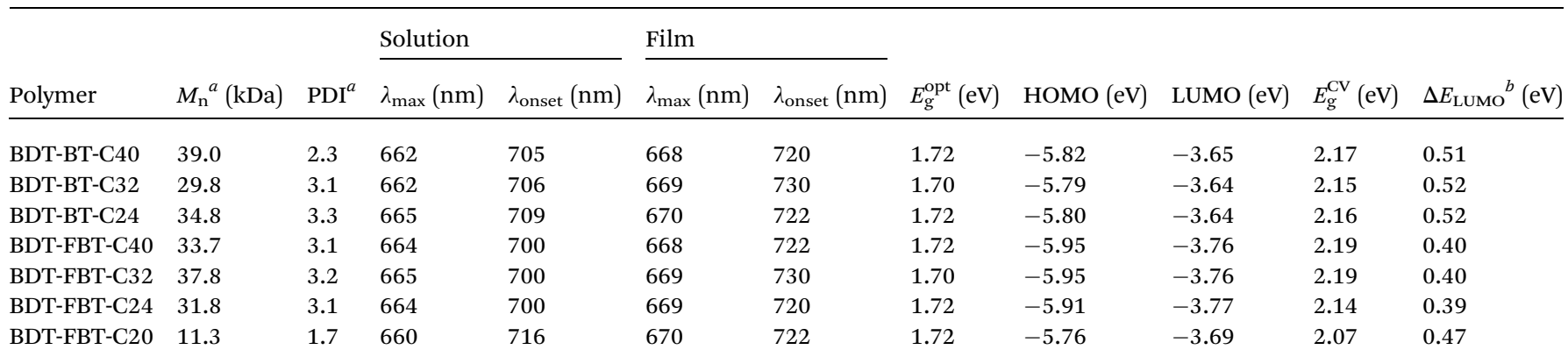

${ }^{a}$ Determined by GPC at $140{ }^{\circ} \mathrm{C}$ using $o$-DCB as the eluent. ${ }^{b} \Delta E_{\mathrm{LUMO}}=E_{\mathrm{LUMO}}$ (polymer) $-E_{\mathrm{LUMO}}([60] \mathrm{PCBM})$. 


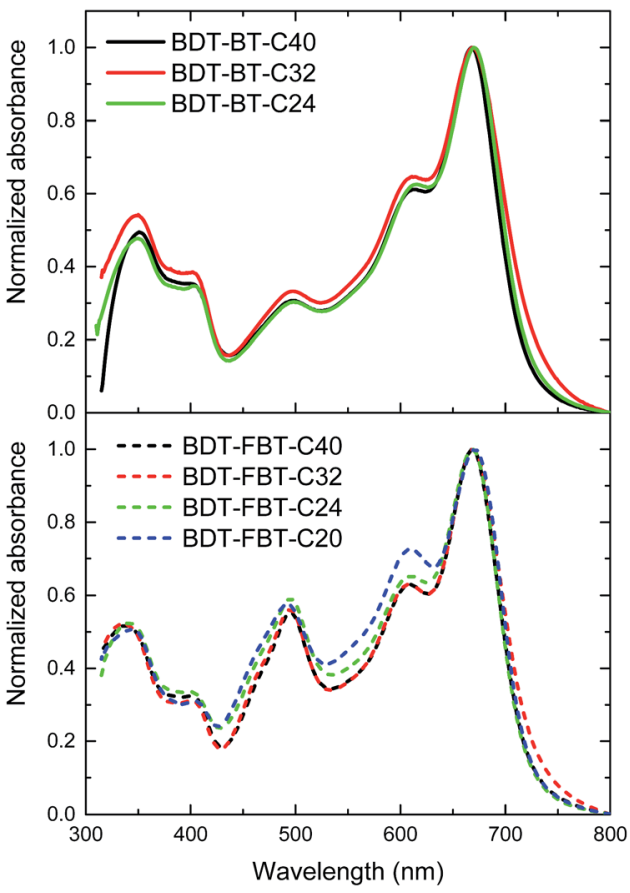

Fig. 1 UV-vis absorption spectra of the polymers in thin films. Films were spin coated at $800 \mathrm{rpm}$ from $8 \mathrm{mg} \mathrm{mL}^{-1}$ solutions in $\mathrm{CB}$ on glass substrates.

FBT-C20 which shows higher-lying frontier orbitals, possibly being caused by its low molecular weight. Generally, polymers within the same system show very similar HOMO levels, signifying that the side chain length has little influence on the energy levels. The electrochemical band gaps of the polymers, which are estimated from the difference between the onsets of the oxidation and reduction waves in the voltammograms, are larger than their optical band gaps. Such a difference is not uncommon and may originate, e.g., from a difference in the relative permittivity in the two experiments and from the exciton binding energy that lowers the optical band gap. ${ }^{66,67}$ The offsets, $\Delta E_{\mathrm{LUMO}}$, between the LUMO levels of the polymers and that of $[6,6]-$ phenyl- $\mathrm{C}_{61}$-butyric acid methyl ester ([60]PCBM) are quite similar within the same polymer system and significantly

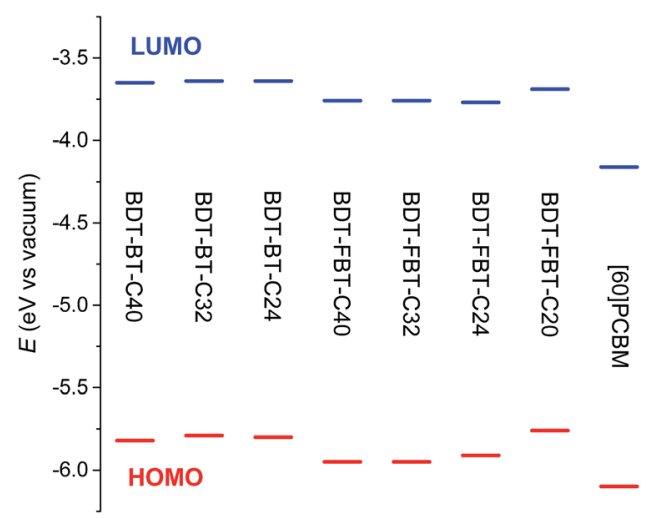

Fig. 2 Energy levels of the polymers determined by cyclic voltammetry using a work function value of $-5.23 \mathrm{eV}$ for $\mathrm{Fc} / \mathrm{Fc}^{+}$. higher than the empirical threshold value of $0.30 \mathrm{eV}$ for efficient exciton dissociation in $\mathrm{BHJ}$ solar cells for all polymers. ${ }^{68}$

\subsection{Photovoltaic properties}

The photovoltaic properties of the polymers were evaluated under simulated AM 1.5G illumination $\left(100 \mathrm{~mW} \mathrm{~cm}{ }^{-2}\right)$ in single-junction PSCs with a conventional polarity device architecture consisting of an indium tin oxide (ITO)/poly(3,4-ethylenedioxythiophene):poly(styrenesulfonate) (PEDOT:PSS) hole collecting bottom contact, a polymer:fullerene photoactive layer, an electron collecting layer (ECL), and an $\mathrm{Al}$ back contact. For a systematic comparison of the photovoltaic performance, the device fabrication was first optimized for BDT-FBT-C24 in terms of the type of fullerene, polymer:fullerene weight ratio, solvent and type of co-solvent, thermal annealing, and ECL/Al contact (Table S1, ESI $\dagger$ ). The best PSCs of BDT-FBT-C24 were fabricated from a $\mathrm{CB}$ solution containing a $1: 2$ weight ratio mixture of BDT-FBT-C24 and[60]PCBM, using poly[(9,9)-bis(3'(N,N-dimethylamino)propyl)-2,7-fluorene]-alt-2,7-(9,9-dioctylfluorene)] (PFN) as the ECL. The same conditions were then applied to all the polymers, with the exception of BDT-FBT-C20 based devices where an evaporated layer of $\operatorname{LiF}(\sim 1 \mathrm{~nm})$ was used as the ECL because the photoactive layer cracked upon deposition of PFN. Typical current density-voltage $(J-V)$ curves are presented in Fig. 3a and c. The external quantum efficiency (EQE) curves are shown in Fig. $3 \mathrm{~b}$ and d, and device parameters are summarized in Table 2. The highest PCEs are achieved for BDT-BT-C24 (5.3\%) and BDT-FBT-C24 (5.1\%). All polymers afford a high $V_{\mathrm{oc}}$ in PSCs, with the remarkable values of 0.98 and $0.99 \mathrm{~V}$ achieved by BDT-FBT-C32 and BDT-FBT-C24, respectively. This shows that the rationale of removing the electronrich thiophene rings from the conjugated backbone of BDTFBT-2 $\mathrm{T}^{59}$ indeed raises the $V_{\mathrm{oc}}$. Generally, BDT-FBT-C $n$ polymers afford higher $V_{\mathrm{oc}}$ than BDT-BT-C $n$ polymers as a result of the electron-withdrawing effect of fluorine atoms. It is worth pointing out that $V_{\text {oc }}$ values up to $0.95 \mathrm{~V}$ are rarely observed for the conjugated polymers with band gaps $<1.75 \mathrm{eV}^{69-71}$

More interestingly, some trends in photovoltaic performances are clearly observable (Fig. 4). For BDT-BT-C $n$ polymers, the $J_{\mathrm{sc}}$ increases significantly from 3.5 to 6.3 , and further to 10.1 $\mathrm{mA} \mathrm{cm}{ }^{-2}$ along with a decreasing length of the side chain. This trend in $J_{\mathrm{sc}}$ is verified by EQE spectra (Fig. 3b). The EQE maxima increase substantially from 0.18 for BDT-BT-C40 to 0.35 for BDT-BT-C32, and further to 0.55 for BDT-BT-C24. The fill factors (FFs) also increase considerably from 0.45 to 0.57 , and further to 0.60 along with decreasing side chain length of the BDT-BT-C $n$ polymers. As a result, the PCEs of the PSCs display a similar trend to $J_{\mathrm{sc}}$ and $\mathrm{FF}$, although the $V_{\mathrm{oc}}$ drops slightly upon decreasing the side chain length. Similar trends in $J_{\mathrm{sc}}, \mathrm{FF}$, and PCE are also observed in the BDT-FBT-Cn system from the polymers of BDT-FBT-C40 to BDT-FBT-C24, but these polymers show opposite trends in $V_{\text {oc }}$. BDT-FBT-C20 shows opposite trends in $J_{\mathrm{sc}}$, FF and PCE. These are attributable to its lower molecular weight and the more disordered substitution pattern of linear and branched side chains. The EQE spectra (Fig. 3b and d) show the relative contribution of the polymer and the 

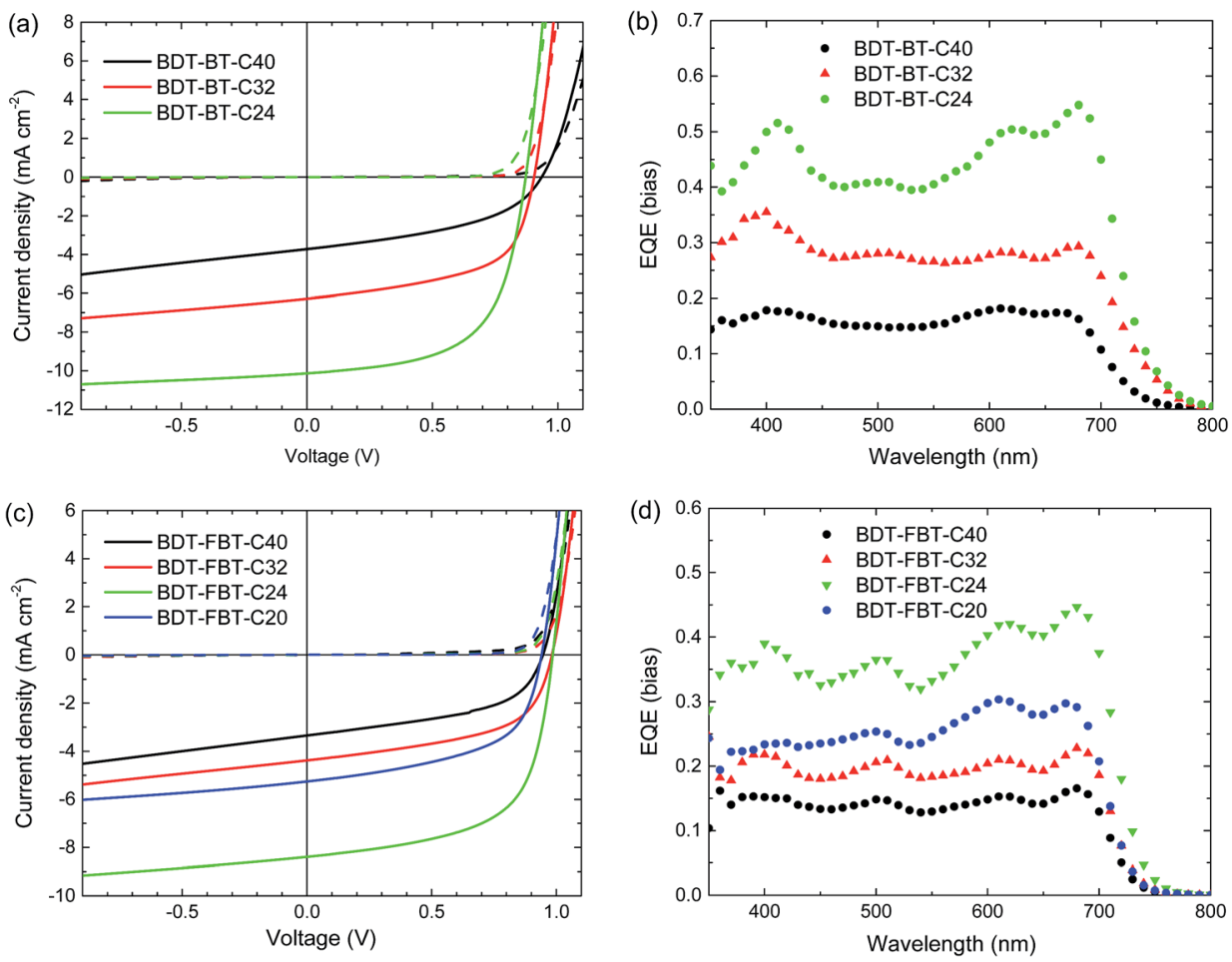

Fig. 3 Current density-voltage (J-V) characteristics of the polymer:[60]PCBM solar cells based on (a) BDT-BT-C40, BDT-BT-C32, and BDT-BTC24, and (c) BDT-FBT-C40, BDT-FBT-C32, BDT-FBT-C24, and BDT-FBT-C20 under AM1.5G illumination (100 mW cm ${ }^{-2}$ ). (b) and (d) EQE curves of the corresponding solar cells.

Table 2 Performance parameters of polymer:[60]PCBM solar cells processed from chlorobenzene based on BDT-BT-C40, BDT-BT-C32, BDTBT-C24, BDT-FBT-C40, BDT-FBT-C32, BDT-FBT-C24, and BDT-FBT-C20 and FET mobilities of the polymers

\begin{tabular}{|c|c|c|c|c|c|c|c|c|c|}
\hline Polymer & ECL & $J_{\mathrm{sc}}{ }^{a}\left(\mathrm{~mA} \mathrm{~cm}^{-2}\right)$ & $\begin{array}{l}J_{\mathrm{sc}}(\mathrm{EQE})^{b} \\
\left(\mathrm{~mA} \mathrm{~cm}{ }^{-2}\right)\end{array}$ & $V_{\mathrm{oc}}{ }^{a}(\mathrm{~V})$ & $\mathrm{FF}^{a}$ & $\operatorname{PCE}^{a}(\%)$ & $\operatorname{PCE}^{c}(\%)$ & $\mathrm{EQE}_{\max }$ & $\begin{array}{l}\mu_{\mathrm{h}} \\
\left(\mathrm{cm}^{2} \mathrm{~V}^{-1} \mathrm{~s}^{-1}\right)\end{array}$ \\
\hline BDT-BT-C40 & PFN & $3.2(3.3=$ & 3.5 & $3 \pm 0.01)$ & $0.45(0.44 \pm 0.01)$ & $1.3(1.3 \pm 0.1)$ & 1.5 & 0.18 & $7.0 \times 10^{-5}$ \\
\hline BDT-BT-C24 & PFN & $8.8(8.7 \pm 0.1)$ & 10.1 & $0.87(0.87 \pm 0.01)$ & $0.60(0.59 \pm 0.01)$ & $4.6(4.5 \pm 0.1)$ & 5.3 & 0.55 & $3.4 \times 10^{-2}$ \\
\hline BDT-FBT-C40 & PFN & $3.0(3.0 \pm 0.1)$ & 3.1 & $0.95(0.93 \pm 0.01)$ & $0.50(0.49 \pm 0.01)$ & $1.4(1.4 \pm 0.1)$ & 1.5 & 0.17 & $4.7 \times 10^{-3}$ \\
\hline BDT-FBT-C32 & PFN & $3.9(3.8 \pm 0.1)$ & 4.4 & $0.98(0.98 \pm 0.01)$ & $0.54(0.54 \pm 0.01)$ & $2.1(2.0 \pm 0.1)$ & 2.3 & 0.23 & $5.0 \times 10^{-3}$ \\
\hline
\end{tabular}

${ }^{a}$ Determined from $J-V$ measurements under simulated solar irradiation. Average values and standard deviation of device statistics from 4 devices are given in parentheses. ${ }^{b}$ Determined by convolution of the EQE with the AM1.5 G solar spectrum. ${ }^{c}$ Calculated using $J_{\mathrm{sc}}(\mathrm{EQE})$.

fullerene constituents to the photocurrent, which is clearly dependent on the side chain length. For example, BDT-BT-C40 and BDT-FBT-C40 based devices exhibit flat EQE curves though both at relatively low EQE values, suggesting balanced contributions of polymers and fullerene absorption to the $J_{\mathrm{sc}}$. However, such a balance is broken upon decreasing the length of side chains with significant imbalance observed in BDT-BTC24, BDT-FBT-C24, and BDT-FBT-C20 based devices. For instance, the BDT-BT-C24 based device shows an EQE maximum of 0.55 for the polymer at $680 \mathrm{~nm}$ but a significantly lower EQE of 0.43 for the fullerene at $440 \mathrm{~nm}$ (absorption valley for the polymer). The experiments on the two polymer systems, BDT-BT-C $n$ and BDT-FBT-C $n$, consistently suggest that any excess of side chain length is detrimental to the photovoltaic performance. Although this study lacks a BDT-BT-C20 polymer, the results on BDT-FBT-C20 clearly indicate that insufficient solubilizing side chains cannot afford high enough molecular weights and thereby produce poor solar cell performance too. We admit that polymers with different side chains may require different processing methods to maximize their performance, solar cells with 1,8-diiodooctane as the solvent additive for active layer processing were also studied. As shown in Table $\mathrm{S} 2, \uparrow$ we did observe changes in the solar cell performance of each polymer, but these results further confirmed the effect of side chain length as discussed above. In our sets of polymers, the incorporation of four hexyl chains is close to optimal. The next question is what causes this interesting effect of the side chain length? 

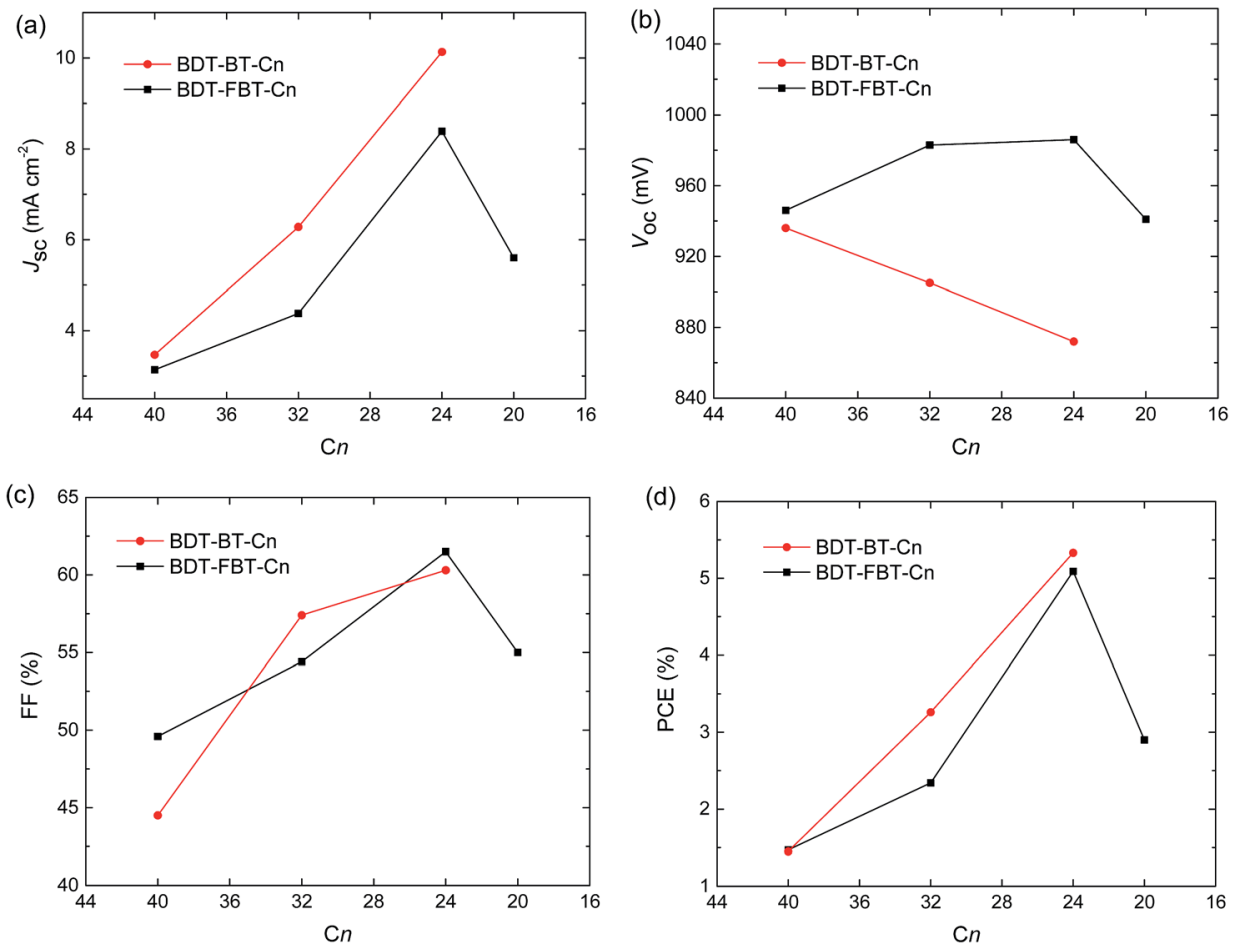

Fig. 4 Solar cell performance parameters vs. number of carbons $(\mathrm{Cn})$ in alkyl side chains of the polymers: (a) $\mathrm{J}_{\mathrm{sc}}-\mathrm{Cn}$, (b) $V_{\text {oc }}-\mathrm{Cn}$, (c) FF-Cn, and (d) PCE-Cn

\subsection{Factors influencing $J_{\mathrm{sc}}, \mathrm{FF}$, and PCE}

The large variation in PCEs of the PSCs originates mainly from the difference in $J_{\mathrm{sc}}$ and FF. In principle, the photocurrent of PSCs depends on the product of the efficiencies of light absorption, exciton diffusion, exciton dissociation, charge transport, and charge collection. The FF of the PSCs depends on the competition between recombination and charge collection, which means that reducing recombination or enhancing charge collection will improve the FF. First, the length of side chains has a somewhat but limited influence on the absorption of the polymer:[60]PCBM blends (Fig. S4, ESI $\dagger$ ). Second, as the measured LUMO levels for the polymers and the $\Delta E_{\text {LUMO }}$ within the same system are very similar (Fig. 2 and Table 1 ), the change of charge generation dynamics upon varying the side chain length can also be ruled out. Third, identical electrode contacts were adopted for all devices (except for BDT-FBT-C20 based devices where $\mathrm{LiF} / \mathrm{Al}$ was used as the cathode contact), so charge collection efficiency at electrodes will not be responsible for the large difference in $J_{\mathrm{sc}}$ and $\mathrm{FF}$. Therefore, the observed difference in device performance upon changing the side chain length of the polymers must be related to the factors that influence exciton diffusion and dissociation, charge carrier transport and recombination.

Further investigation was first carried out by measuring the hole mobility of the polymers in field effect transistors (FETs) to investigate differences in charge transport (Fig. S5, ESI $\dagger$ ). As shown in Table 2, the FET mobilities of both BDT-BT-Cn polymers and BDT-FBT-Cn polymers show a clear dependence on the length of side chain. In the BDT-BT-Cn system, the hole mobility is $7.0 \times 10^{-5}, 7.8 \times 10^{-4}$, and $3.4 \times 10^{-2} \mathrm{~cm}^{2} \mathrm{~V}^{-1} \mathrm{~s}^{-1}$ for BDT-BT-C40, BDT-BT-C32, and BDT-BT-C24, respectively. In the BDT-FBT-Cn system, the hole mobility is $4.7 \times 10^{-3}, 5.0 \times$ $10^{-3}$, and $8.4 \times 10^{-3} \mathrm{~cm}^{2} \mathrm{~V}^{-1} \mathrm{~s}^{-1}$ for BDT-FBT-C40, BDT-FBTC32, and BDT-FBT-C24, respectively. This difference in charge transport abilities can thus, at least partially, account for the variation in $J_{\mathrm{sc}}$ and $\mathrm{FF}$ upon changing the length of side chains of the polymers. Notably, BDT-FBT-C20 exhibits the highest hole mobility of $1.0 \times 10^{-1} \mathrm{~cm}^{2} \mathrm{~V}^{-1} \mathrm{~s}^{-1}$, which is probably because of less entanglement of polymer chains due to low molecular weight and suggests that there are other factors that affect photovoltaic properties of BDT-FBT-C20.

Keeping the large difference in the FFs of the PSCs in mind, we speculate that the side chain length in polymers has a substantial influence on the recombination losses as charge recombination losses manifest themselves most significantly in the $\mathrm{FF}^{72}$ To investigate how the side chain length affects the recombination losses, EQEs of the solar cells measured under monochromatic light with or without bias light were analyzed. Under enhanced bias illumination of a $532 \mathrm{~nm}$ laser, bimolecular recombination becomes more considerable as the significant enhancement of charge carrier concentration. Because the EQE is measured by using a lock-in technique, it provides a measure of the differential photocurrent $\left(\mathrm{d} J_{\mathrm{ph}} / \mathrm{d} I\right)$ rather than of the photocurrent $\left(J_{\mathrm{ph}}\right)$. For solar cells with a sublinear lightintensity dependence, $J_{\mathrm{ph}} \sim I^{\alpha}(\alpha<1)$, this results in an EQE that is less than the actual EQE. ${ }^{73}$ Importantly, the ratio between the EQE measured under light bias and without light bias (denoted as $\left.\rho=\mathrm{EQE}_{\text {bias }} / \mathrm{EQE}_{\text {nobias }}\right)$ reflects the bimolecular recombination losses in the PSCs. We have previously reported that the 
bimolecular recombination efficiency $\left(\eta_{\mathrm{BR}}\right)$ at higher light intensities can be quantified by $\eta_{\mathrm{BR}}=1-\rho,{ }^{74}$ implying that a smaller $\rho$ implies more serious bimolecular recombination. Fig. 5 shows the average values of the $\rho$ in the wavelength range from 400 to $750 \mathrm{~nm}$ of the PSCs. The original biased and unbiased EQEs of the devices are shown in Fig. S6 (ESI $\dagger$ ). The average value of $\rho$ increases drastically from 0.862 for BDT-BTC40 to 0.929 for BDT-BT-C32, and further to 0.983 for BDT-BTC24. A similar trend is also observed in BDT-FBT-Cn polymers (where $\rho$ is 0.935 for BDT-FB4-C40, 0.945 for BDT-FBT-C32, and 0.970 for BDT-FBT-C24). Noticeably, BDT-FBT-C20 also has a low $\rho$ value of 0.899 , despite its relatively high hole mobility. We thus see that reducing the side chain length correlates with less bimolecular recombination losses in PSCs, except for BDTFBT-C20. Moreover, the changes in the bimolecular recombination efficiency correlate with the variation in $\mathrm{FF}$ and in $J_{\mathrm{sc}}$ upon changing the side chain length (compare Fig. 4 and 5). It is

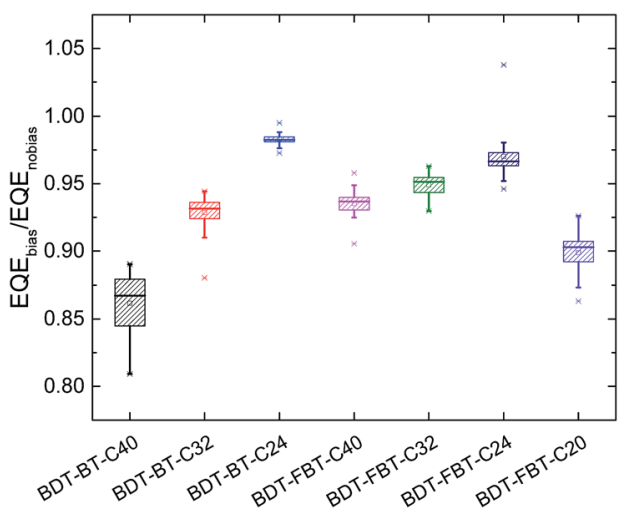

Fig. 5 Average $\mathrm{EQE}_{\text {bias }} / \mathrm{EQE}_{\text {no bias }}$ values of polymer:[60]PCBM solar cells based on BDT-BT-C40, BDT-BT-C32, BDT-BT-C24, BDT-FBTC40, BDT-FBT-C32, BDT-FBT-C24, and BDT-FBT-C20. worth pointing out that other recombination processes may also account for the difference in the $J_{\mathrm{sc}}$ and FF of the PSCs. ${ }^{75}$

It is worth mentioning that no clear and consistent trend in the $V_{\mathrm{oc}}$ of the two sets of polymers is observed. Generally, the $V_{\mathrm{oc}}$ of organic solar cells is affected by several factors, such as HOMO and LUMO energy levels of the donor and acceptor, charge transport layers, charge generation and recombination, energetic disorder and the presence of defect states as well as the bulk heterojunction morphology and the crystallinity of the polymer. An insightful understanding of the change of $V_{\mathrm{oc}}$ upon changing the side chain length would require further investigation.

\subsection{Polymer crystallinity and BHJ morphology}

Having established that the side chain length affects charge transport abilities and bimolecular recombination losses of the PSCs, we next attempt to correlate these observables with the morphological characteristics of the polymer:fullerene $\mathrm{BHJ}$ films, as the BHJ morphology significantly influences exciton diffusion, charge dissociation, and charge transport.

The morphology of the polymer:[60]PCBM BHJ films was studied by atomic force microscopy (AFM) and transmission electron microscopy (TEM). AFM phase images (Fig. 6) indicate serious phase separation and large domain sizes in BDT-BT-C40 and BDT-FBT-C40 based BHJ films. Smaller nanoscale domains and a more continuous interpenetrating network are observed when the side chains of the polymers are shorter. Specifically, finely dispersed structures appear in the phase images of the BDT-BT-C24 and BDT-FBT-C24 based BHJ films. Further shortening the side chain leads to an almost featureless surface morphology for the BDT-FBT-C20 based BHJ film. In AFM height images (Fig. S7, ESI $\dagger$ ), a gradual reduction of the root mean square roughness $\left(R_{\mathrm{q}}\right)$ of $4.94,3.78$, and $2.54 \mathrm{~nm}$ is recorded for the BHJ films of BDT-BT-C40, BDT-BT-C32, and
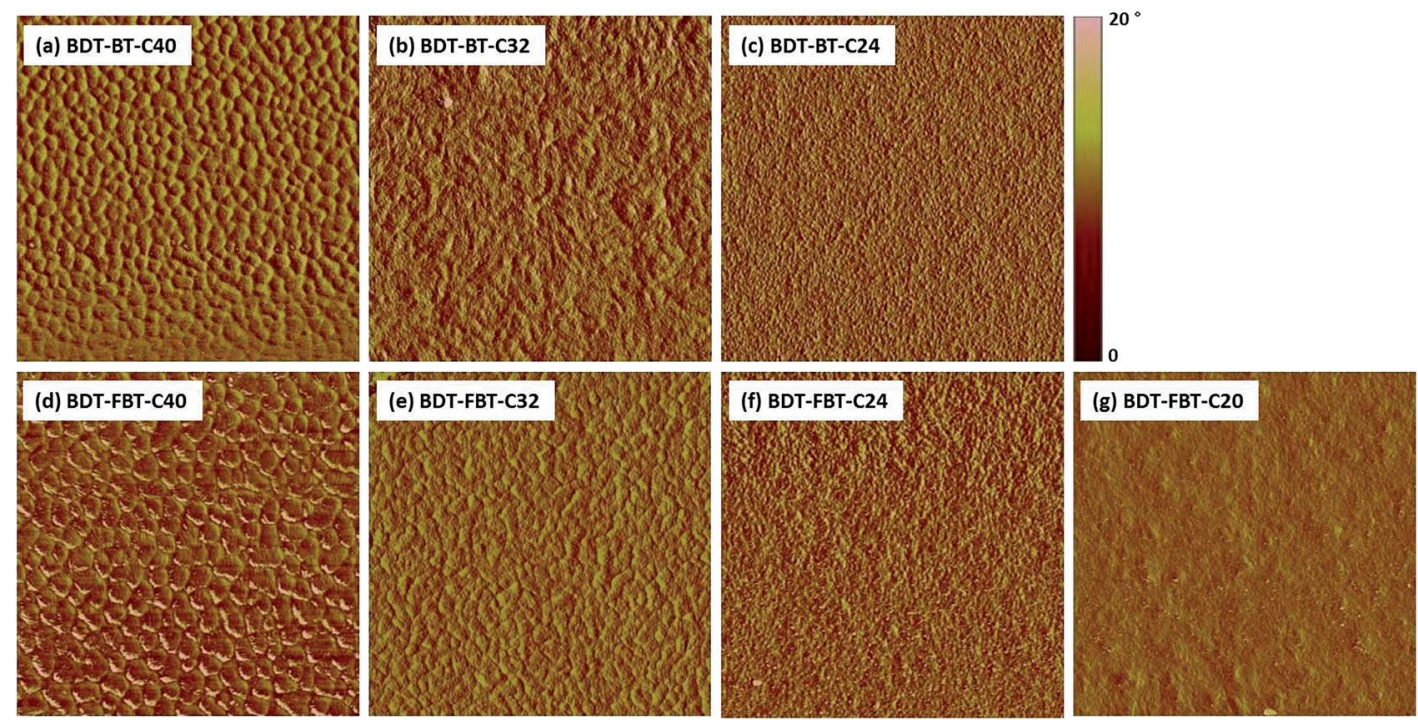

Fig. 6 AFM phase images $\left(5 \times 5 \mu \mathrm{m}^{2}\right.$, vertical scale $\left.20^{\circ}\right)$ of the polymer:[60]PCBM blend films spin-coated from CB for BDT-BT-C40 (a), BDTBT-C32 (b), BDT-BT-C24 (c), BDT-FBT-C40 (d), BDT-FBT-C32 (e), BDT-FBT-C24 (f), and BDT-FBT-C20 (g). 

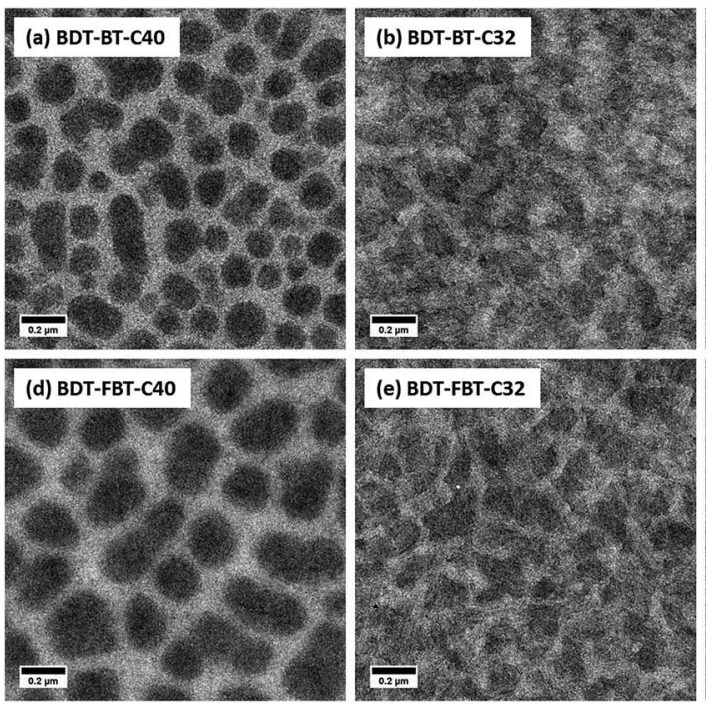
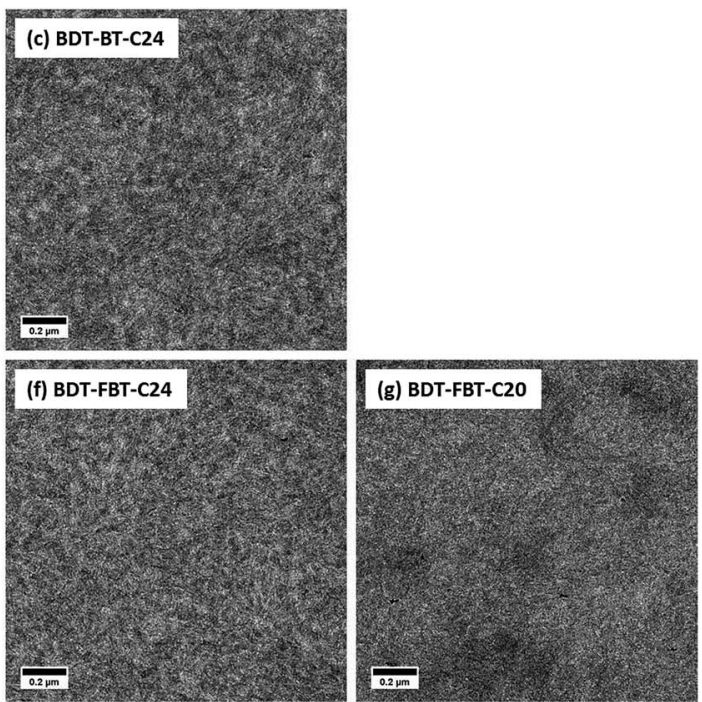

Fig. 7 Bright field TEM images of the polymer:[60]PCBM blend films spin-coated from CB for BDT-BT-C40 (a), BDT-BT-C32 (b), BDT-BT-C24 (c), BDT-FBT-C40 (d), BDT-FBT-C32 (e), BDT-FBT-C24 (f), and BDT-FBT-C20 (g). Image size: $1.5 \times 1.5 \mu \mathrm{m}^{2}$; scale bar: $200 \mathrm{~nm}$.

BDT-BT-C24, respectively. A similar trend is observed in the BDT-FBT-Cn system, with $R_{\mathrm{q}}$ values of $6.10,3.29$, and $2.54 \mathrm{~nm}$ for the BHJ films of BDT-FBT-C40, BDT-FBT-C32, and BDT-FBTC24, respectively. But the roughness of the BDT-FBT-C20:[60] PCBM film is increased to $4.12 \mathrm{~nm}$.

The TEM images confirm the morphological changes of the $\mathrm{BHJ}$ films with the side chain length variation (Fig. 7). Serious phase separation and large domain size are clear in both BDTBT-C40:[60]PCBM and BDT-FBT-C40:[60]PCBM films. Such large domains result from liquid-liquid phase separation during spin coating. ${ }^{76}$ Significantly, smaller domain size and better interconnectivity are observed in BDT-BT-C32:[60]PCBM and BDT-FBT-C32:[60]PCBM films. Moreover, finely dispersed structures are observable in BDT-BT-C24 and BDT-FBT-C24 based $\mathrm{BHJ}$ films. The transition from a liquid-liquid phase separated morphology to a finely dispersed structure when reducing the side chains and thereby solubility is consistent with the fact that liquid-liquid phase separation is suppressed when the polymer has an increased tendency to aggregate. ${ }^{77}$ No significant phase separation is observed in the BDT-FBT-C20 based BHJ film. Recently, it was shown that other low molecular weight conjugated polymers can form solid films with crystalline domains that are disconnected from each other. ${ }^{\mathbf{6 1 , 7 8 , 7 9}}$ Interestingly, the high-magnification TEM-images (Fig. S8, ESI $\dagger$ ) clearly show crystalline fringes for all polymers. In short, significant differences in the morphology of the BHJ films are found with changing the side chain length. These are consistent with the difference in the device performance of the polymers.

The data show that an insufficient side chain length yields low molecular weight polymers or even insoluble polymers that cannot be used. The low molecular weight results in poor phase interconnectivity, low domain purity, unfavorable structural orientation and so on, which have already been well studied. ${ }^{61,80,81}$ On the other hand, too long side chains produce too soluble polymers, which will affect drying kinetics and selforganization of the $\mathrm{BHJ}$ films during spin-coating as well as the compatibility between the polymers and fullerene. As a result, a suboptimal BHJ film morphology with serious phase separation and large domain size will be formed. In these liquidliquid phase separated blends, charge generation mainly occurs in the continuous mixed polymer-fullerene phase, but because most fullerenes are assembled in the droplet domains, the electron transport in the mixed phase is hampered which results in significant bimolecular recombination. ${ }^{76,82}$ An optimal side chain length is thus required to balance solubility such that the right microstructure can be formed in $\mathrm{BHJ}$ films.

\section{Conclusions}

Two sets of conjugated polymers based on BDT and BT or FBT with different alkyl side chain lengths were designed and synthesized to systematically investigate the effect of side chain length on the photovoltaic properties of the polymers. Our results suggest strong interdependency between the side chain length of conjugated polymers and photovoltaic performances of the resulting $\mathrm{BHJ}$ solar cells. Too long side chains lead to deteriorated charge transport, a suboptimal BHJ morphology featuring serious phase separation, considerable charge carrier recombination, and consequently poor photovoltaic performances. On the other hand, too short side chains cannot afford high enough solubility and molecular weight for the resulting polymers and will definitely produce poor solar cell performance as well. ${ }^{\mathbf{8 0 , 8 1}}$ Selecting a suitable side chain length is thus of significant importance to maximize the potential of conjugated polymers in BHJ solar cells.

A recent statistical analysis revealed strong correlations between PCEs and morphology-dominated properties $\left(J_{\text {sc }}\right.$ and FF) and weak correlations between PCEs and energy level relevant properties $\left(V_{\mathrm{oc}}\right) .^{83}$ As demonstrated here, there is a strong interdependency between the side chain length and morphology-dominated properties $\left(J_{\text {sc }}\right.$ and FF) as well. Side chain optimization of conjugated polymers in combination 
with efficient optimization of the active layer microstructure and morphology will thus be highly fruitful to future PSC efficiency gains. Our preliminary studies also suggest that further performance enhancements for BDT-BT-Cn and BDT-FBT-Cn polymers are possible through morphology optimization (Table S2, Fig. S9, and Table S3, ESI $\dagger$ ). In the past few years, the development of new materials in the PSC community has centered on the design/manipulation of conjugated backbones and energy level tuning. Generally, a limited variety of standard side-chain substituents or even more typically only one kind of side chain is introduced for a new polymer framework unless solubility/processability proves problematic. As a result, the potential of many polymer systems was not fully explored due to taking little account of side chain optimization. The observations in this paper are based on a relatively large number of closely related polymers and the results provide a consistent view on the effects of side chain length on device performance that will support the molecular design of new photovoltaic active semiconducting conjugated polymers in future.

\section{Experimental section}

\subsection{Synthesis}

All synthetic procedures were performed under an argon atmosphere. All reactants and reagents are commercially available and used as received, unless otherwise specified. Solvents were dried over 4 Å molecular sieves. [60]PCBM (purity of $99 \%$ ) and [70]PCBM (purity of 99\%) were purchased from Solenne BV. 2,6-Bis(trimethyltin)-4,8-di(2,3-didecylthiophen-5yl)-benzo[1,2- $\left.b: 4,5-b^{\prime}\right]$ dithiophene (M1), 2,6-bis(trimethyltin)4,8-di(2,3-dioctylthiophen-5-yl)-benzo[1,2- $\left.b: 4,5-b^{\prime}\right]$ dithiophene (M2), 2,6-bis(trimethyltin)-4,8-di(2,3-dihexylthiophen-5-yl)benzo[1,2- $\left.b: 4,5-b^{\prime}\right]$ dithiophene (M3), and 5,6-difluoro-4,7dibromobenzo[2,1,3]thiadiazole (M6) were purchased from SunaTech Inc. 2,6-Bis(trimethyltin)-4,8-di(2-(2-ethylhexyl)thiophen-5-yl)-benzo[1,2- $\left.b: 4,5-b^{\prime}\right]$ dithiophene (M4) was purchased from Solarmer Materials, Inc. 5,6-Dibromobenzo[2,1,3]thiadiazole (M5) was synthesized according to our previous method.

4.1.1. General polymerization procedures. To a degassed solution of bis(trimethyltin) BDT monomer(s) (0.09 mmol), and dibrominated BT or FBT monomers $(0.09 \mathrm{mmol})$ in anhydrous toluene $(1.8 \mathrm{~mL})$ and anhydrous DMF $(0.2 \mathrm{~mL})$, tris(dibenzylideneacetone)-dipalladium(0) $(2.47 \mathrm{mg}, 0.0027 \mathrm{mmol})$ and tri $(o$ tolylphosphine) (6.57 mg, $0.0216 \mathrm{mmol})$ were added. The mixture was stirred at $115{ }^{\circ} \mathrm{C}$ for 18 hours, after which 2 -(tributylstannyl)thiophene and 2-bromothiophene were sequentially added to the reaction with a 2 hours interval. After another 2 hours, the reaction mixture was diluted with $o$-DCB, and refluxed with EDTA $(100 \mathrm{mg})$ for 2 hours. Upon cooling, the reaction mixture was precipitated in methanol and filtered through a Soxhlet thimble. The polymer was subjected to sequential Soxhlet extraction with acetone, hexane, dichloromethane and chloroform under argon protection. The chloroform fraction was concentrated under reduced pressure and precipitated in methanol to obtain the resulting polymer.

4.1.2. Poly\{(4,8-di(2,3-didecylthiophen-5-yl)-benzo[1,2-b:4,5- $\left.b^{\prime}\right]$ dithiophen-2,6-diyl)-alt-(benzo[2,1,3]thiadiazole-4,7-diyl)\} (BDT-BT-
C40). BDT-BT-C40 was synthesized from M1 and M5 as a dark shiny solid (75 mg, yield 80\%). $M_{\mathrm{n}}=39.0 \mathrm{~kg} \mathrm{~mol}^{-1}$, PDI $=2.3$.

4.1.3. Poly $\left\{\left(4,8-d i(2,3-d i o c t y l t h i o p h e n-5-y l)-b e n z o\left[1,2-b: 4,5-b^{\prime}\right]-\right.\right.$ dithiophen-2,6-diyl)-alt-(benzo[2,1,3]thiadiazole-4,7-diyl)\} (BDT-BTC32). BDT-BT-C32 was synthesized from M2 and M5 as a dark shiny solid (62 mg, yield 66\%). $M_{\mathrm{n}}=29.8 \mathrm{~kg} \mathrm{~mol}^{-1}$, and PDI $=3.1$.

4.1.4. Poly $\left\{\left(4,8-d i(2,3-d i h e x y l t h i o p h e n-5-y l)-b e n z o\left[1,2-b: 4,5-b^{\prime}\right]-\right.\right.$ dithiophen-2,6-diyl)-alt-(benzo[2,1,3]thiadiazole-4,7-diyl)\} (BDT-BTC24). BDT-BT-C24 was synthesized from M3 and M5 as a dark shiny solid (90 mg, yield 95\%). $M_{\mathrm{n}}=34.8 \mathrm{~kg} \mathrm{~mol}^{-1}$, and PDI $=3.3$.

4.1.5. Poly $\left\{\left(4,8-d i(2,3-d i d e c y l t h i o p h e n-5-y l)-b e n z o\left[1,2-b: 4,5-b^{\prime}\right]-\right.\right.$ dithiophen-2,6-diyl)-alt-(5,6-difluorobenzo[2,1,3]thiadiazole-4,7diyl)\} (BDT-FBT-C40). BDT-FBT-C40 was synthesized from M1 and M6 as a dark shiny solid (63 mg, yield 65\%). $M_{\mathrm{n}}=33.7 \mathrm{~kg}$ $\mathrm{mol}^{-1}$, and PDI $=3.1$.

4.1.6. Poly\{(4,8-di(2,3-dioctylthiophen-5-yl)-benzo[1,2-b:4,5- $\left.b^{\prime}\right]$ dithiophen-2,6-diyl)-alt-(5,6-difluorobenzo[2,1,3]thiadiazole-4,7diyl)\} (BDT-FBT-C32). BDT-FBT-C32 was synthesized from M2 and M6 as a dark shiny solid (62 mg, yield 63\%). $M_{\mathrm{n}}=37.8 \mathrm{~kg}$ $\mathrm{mol}^{-1}$, and PDI $=3.2$.

4.1.7. Poly\{(4,8-di(2,3-dihexylthiophen-5-yl)-benzo[1,2-b:4,5- $\left.b^{\prime}\right]$ dithiophen-2,6-diyl)-alt-(5,6-difluorobenzo[2,1,3]thiadiazole-4,7diyl)\} (BDT-FBT-C24). BDT-FBT-C24 was synthesized from M3 and M6 as a dark shiny solid (64 mg, yield 65\%). $M_{\mathrm{n}}=31.8 \mathrm{~kg}$ $\mathrm{mol}^{-1}$, and PDI $=3.1$.

4.1.8. Poly\{[2-(4,8-di(2,3-dihexylthiophen-5-yl)-benzo[1,2-b:4,5$\left.b^{\prime}\right]$ dithiophen-6-yl))-(4-(5,6-difluorobenzo[2,1,3]thiadiazole-7yl)]-ran-[2-(4,8-di(2-ethylhexylthiophen-5-yl)-benzo[1,2-b:4,5- $\left.b^{\prime}\right]$ dithiophen-6-yl))-(4-(5,6-difluorobenzo[2,1,3]thiadiazole-7-yl)]\} (BDT-FBT-C20). BDT-FBT-C20 was synthesized from M3, M4 and M6 with the feeding ratio M3 : M4 : M6 $=0.5: 0.5: 1$ as a dark shiny solid ( $85 \mathrm{mg}$, yield $89 \%$ ). $M_{\mathrm{n}}=11.3 \mathrm{~kg} \mathrm{~mol}^{-1}$, and PDI $=1.7$.

4.1.9. Poly $\left\{\left(4,8-d i(2-e t h y l h e x y l t h i o p h e n-5-y l)-b e n z o\left[1,2-b: 4,5-b^{\prime}\right]-\right.\right.$ dithiophen-2,6-diyl)-alt-(5,6-difluorobenzo[2,1,3]thiadiazole-4,7-diyl)\} (BDT-FBT-C16). The polymerization of BDT-FBT-C16 was conducted from M4 and M6 according to the method described above. The precipitate resulted is insoluble in any solvent.

\subsection{Measurements and characterization}

Molecular weights and polydispersity index (PDI) were determined by gel permeation chromatography (GPC) at $140{ }^{\circ} \mathrm{C}$ on a PL-GPC 120 system using a PL-GEL $10 \mu \mathrm{m}$ MIXED-B column and 1,2-dichlorobenzene (o-DCB) as the eluent against polystyrene standards. All the polymer samples were dissolved in $o$ DCB at $140{ }^{\circ} \mathrm{C}$ overnight and the solutions were filtered through PTFE filters $(0.2 \mu \mathrm{m})$ prior to injection. UV-visible spectra were recorded on a Perkin Elmer Lambda 900 UV/vis/near IR spectrophotometer at room temperature unless otherwise noted. All solution UV-vis experiments were performed in $o$-DCB with a sample concentration of $0.05 \mathrm{mg} \mathrm{mL}^{-1}$. Films were prepared by spin coating $o$-DCB solutions on glass substrates. Cyclic voltammetry (CV) studies were performed with a scan rate of 0.1 $\mathrm{V} \mathrm{s}^{-1}$ under an inert atmosphere with $1 \mathrm{M}$ tetrabutylammonium hexafluorophosphate in acetonitrile as the electrolyte. The working electrode was an indium tin oxide (ITO) bar and the 
counter electrode was a silver electrode. A silver wire coated with silver chloride $(\mathrm{Ag} / \mathrm{AgCl})$ was used as the quasi-reference electrode in combination with $\mathrm{Fc} / \mathrm{Fc}^{+}$as an internal standard. The samples were spin coated on the top of the ITO working electrode to form $\sim 10 \mathrm{~nm}$ thick films. Atomic force microscopy (AFM) was performed on an extended Veeco MultiMode AFM connected to a Nanoscope III controller in tapping mode using PPP-NCH-50 probes (Nanosensors). Transmission electron microscopy (TEM) was performed on a Tecnai $\mathrm{G}^{2}$ Sphera transmission electron microscope (FEI) operating at $200 \mathrm{kV}$. Field-effect transistors (FETs) were fabricated in a bottomcontact top-gate configuration on pre-cleaned glass substrates. Source and drain contacts were defined by evaporating chromium $(2 \mathrm{~nm})$ and gold $(40 \mathrm{~nm})$ through a shadow mask. Subsequently, the polymer was applied by spin coating in a nitrogen-filled glove-box from a $3 \mathrm{mg} \mathrm{mL}^{-1}$ solution in $o$-DCB, at room temperature, for $60 \mathrm{~s}$ at $1500 \mathrm{rpm}$. The polymer film was annealed at $200{ }^{\circ} \mathrm{C}$ for $20 \mathrm{~min}$ and cooled down to room temperature slowly. Next, a layer of CYTOP (AGC Chemicals) was spin coated as a gate dielectric. This spin coating step was performed at $1500 \mathrm{rpm}$ for $60 \mathrm{~s}$ in a nitrogen-filled glovebox. The CYTOP was annealed at $80{ }^{\circ} \mathrm{C}$ for $10 \mathrm{~min}$ and at $200{ }^{\circ} \mathrm{C}$ for $15 \mathrm{~min}$. The top gate electrode was applied by thermal evaporation of gold (40 $\mathrm{nm}$ ) through a shadow mask. The transistors were electrically characterized with a Keithley 2400 measuring unit. The length and the width of the transistor channel are 70 $\mu \mathrm{m}$ and $1000 \mu \mathrm{m}$, respectively.

\subsection{Fabrication and characterization of solar cells}

Photovoltaic devices were made by spin coating poly(3,4-ethylenedioxythiophene):poly(styrene sulfonate) (PEDOT:PSS) (Clevios $\mathrm{P}$, VP AI 4083) onto pre-cleaned, patterned indium tin oxide (ITO) substrates in air (14 $\Omega$ per square) (Naranjo Substrates). The polymer-fullerene photoactive layers were deposited by spin coating in air from the solutions containing the corresponding polymers and [60]PCBM or [70]PCBM with different content ratios at room temperature. Unless indicated otherwise, no thermal annealing was applied to the blend films. The thickness of active layer films was controlled by the spin speed. Before the evaporation of the Al electrode, a thin PFN layer was spin-coated on the top of the active layer from its methanol solution $\left(0.2 \mathrm{mg} \mathrm{mL}^{-1}\right)$ at $3000 \mathrm{rpm}$. For BDT-FBT-C20:PCBM, $\mathrm{LiF}(1 \mathrm{~nm})$ was evaporated to serve as the ECL due to the film cracking upon PFN solution deposition. Finally, Al (100 nm) was deposited by vacuum evaporation at $\sim 3 \times 10^{-7}$ mbar as the back electrode. The active area of the cells was 0.09 or $0.16 \mathrm{~cm}^{2}$, which provided similar results. Current density-voltage $(J-V)$ curves were measured under simulated solar light $(100 \mathrm{~mW}$ $\mathrm{cm}^{-2}$ ) from a tungsten-halogen lamp filtered by using a Hoya LB100 daylight using a Keithley 2400 source meter. No mismatch correction was done. All measurements were conducted in a nitrogen-filled glovebox. The accurate short-circuit current density $\left(J_{\mathrm{sc}}\right)$ was determined from the EQE by convolution with the AM 1.5G solar spectrum. External quantum efficiency (EQE) measurements were performed in a homebuilt setup, with the devices kept in a nitrogen filled box with a quartz window and illuminated through an aperture of $2 \mathrm{~mm}$. Mechanically modulated (Stanford Research, SR 540) monochromatic (Oriel, Cornerstone 130) light from a $50 \mathrm{~W}$ tungsten halogen lamp (Osram 64610) was used as probe light, in combination with continuous bias light from a solid state laser (B\&W Tek Inc. $532 \mathrm{~nm}, 30 \mathrm{~mW}$ ). The intensity of the bias laser light was adjusted using a variable-neutral density filter. The response was recorded as the voltage over a $50 \Omega$ resistance, using a lock-in amplifier (Stanford Research Systems SR 830). For all the single junction devices, the measurements were carried out under representative illumination intensities (AM1.5G equivalent, provided by the $532 \mathrm{~nm}$ laser).

\section{Acknowledgements}

We thank Ralf Bovee for GPC analysis, Wijnand Dijkstra and Marco van der Sluis for AFM measurements. C. Duan thanks Fei Huang and Zhicheng $\mathrm{Hu}$ of the South China University of Technology for providing PFN. The work was performed in the framework of the Mujulima project that received funding from the European Commission's Seventh Framework Programme (Grant Agreement No. 604148). The work of JJVF forms part of the research programme of the Dutch Polymer Institute (DPI), project \#734. The research leading to these results has also received funding from the European Research Council under the European Union's Seventh Framework Programme (FP/ 2007-2013)/ERC Grant Agreement No. 339031. The research forms part of the Solliance OPV program and has received funding from the Ministry of Education, Culture and Science (Gravity program 024.001.035).

\section{Notes and references}

1 S. Günes, H. Neugebauer and N. S. Sariciftci, Chem. Rev., 2007, 107, 1324.

2 L. Dou, J. You, Z. Hong, Z. Xu, G. Li, R. A. Street and Y. Yang, Adv. Mater., 2013, 25, 6642.

3 S.-H. Liao, H.-J. Jhuo, P.-N. Yeh, Y.-S. Cheng, Y.-L. Li, Y.-H. Lee, S. Sharma and S.-A. Chen, Sci. Rep., 2014, 4, 6813.

4 Y. Liu, J. Zhao, Z. Li, C. Mu, W. Ma, H. Hu, K. Jiang, H. Lin, H. Ade and H. Yan, Nat. Commun., 2014, 5, 5293.

5 J.-D. Chen, C. Cui, Y.-Q. Li, L. Zhou, Q.-D. Ou, C. Li, Y. Li and J.-X. Tang, Adv. Mater., 2015, 27, 1035.

6 S. Zhang, L. Ye, W. Zhao, B. Yang, Q. Wang and J. Hou, Sci. China: Chem., 2015, 58, 248.

7 Z. He, B. Xiao, F. Liu, H. Wu, Y. Yang, S. Xiao, C. Wang, T. P. Russell and Y. Cao, Nat. Photonics, 2015, 9, 174.

8 V. Vohra, K. Kawashima, T. Kakara, T. Koganezawa, I. Osaka, K. Takimiya and H. Murata, Nat. Photonics, 2015, 9, 403.

9 Y. Liang, Z. Xu, J. Xia, S.-T. Tsai, Y. Wu, G. Li, C. Ray and L. Yu, Adv. Mater., 2010, 22, E135.

10 S.-H. Liao, H.-J. Jhuo, Y.-S. Cheng and S.-A. Chen, Adv. Mater., 2013, 25, 4766.

11 L. Ye, S. Zhang, W. Zhao, H. Yao and J. Hou, Chem. Mater., 2014, 26, 3603.

12 H.-Y. Chen, J. Hou, S. Zhang, Y. Liang, G. Yang, Y. Yang, L. Yu, Y. Wu and G. Li, Nat. Photonics, 2009, 3, 649. 
13 B. A. Collins, Z. Li, J. R. Tumbleston, E. Gann, C. R. McNeill and H. Ade, Adv. Energy Mater., 2013, 3, 65.

14 G. J. Hedley, A. J. Ward, A. Alekseev, C. T. Howells, E. R. Martins, L. A. Serrano, G. Cooke, A. Ruseckas and I. D. W. Samuel, Nat. Commun., 2013, 4, 2867.

15 W. Li, K. H. Hendriks, A. Furlan, W. S. C. Roelofs, S. C. J. Meskers, M. M. Wienk and R. A. J. Janssen, Adv. Mater., 2014, 26, 1565.

16 J. R. Tumbleston, B. A. Collins, L. Yang, A. C. Stuart, E. Gann, W. Ma, W. You and H. Ade, Nat. Photonics, 2014, 8, 385.

17 Y. Huang, E. J. Kramer, A. J. Heeger and G. C. Bazan, Chem. Rev., 2014, 114, 7006.

18 S. R. Cowan, W. L. Leong, N. Banerji, G. Dennler and A. J. Heeger, Adv. Funct. Mater., 2011, 21, 3083.

19 E. T. Hoke, K. Vandewal, J. A. Bartelt, W. R. Mateker, J. D. Douglas, R. Noriega, K. R. Graham, J. M. J. Fréchet, A. Salleo and M. D. McGehee, Adv. Energy Mater., 2013, 3, 220.

20 R. A. J. Janssen and J. Nelson, Adv. Mater., 2013, 25, 1847.

21 J. A. Bartelt, Z. M. Beiley, E. T. Hoke, W. R. Mateker, J. D. Douglas, B. A. Collins, J. R. Tumbleston, K. R. Graham, A. Amassian, H. Ade, J. M. J. Fréchet, M. F. Toney and M. D. McGehee, Adv. Energy Mater., 2013, 3,364 .

22 T. Heumueller, W. R. Mateker, I. T. Sachs-Quintana, K. Vandewal, J. A. Bartelt, T. M. Burke, T. Ameri, C. J. Brabec and M. D. McGehee, Energy Environ. Sci., 2014, 7, 2974.

23 J. Chen and Y. Cao, Acc. Chem. Res., 2009, 42, 1709.

24 Y. Y. Liang and L. P. Yu, Acc. Chem. Res., 2010, 43, 1227.

25 P. M. Beaujuge and J. M. J. Fréchet, J. Am. Chem. Soc., 2011, 133, 20009.

26 C. H. Duan, F. Huang and Y. Cao, J. Mater. Chem., 2012, 22, 10416.

27 Y. Li, Acc. Chem. Res., 2012, 45, 723.

28 H. X. Zhou, L. Q. Yang and W. You, Macromolecules, 2012, 45, 607.

29 E. Wang, W. Mammo and M. R. Andersson, Adv. Mater., 2014, 26, 1801.

30 L. Ye, S. Zhang, L. Huo, M. Zhang and J. Hou, Acc. Chem. Res., 2014, 47, 1595.

31 E. E. Havinga, W. ten Hoeve and H. Wynberg, Synth. Met., 1993, 55, 299.

32 A. Dhanabalan, J. K. J. van Duren, P. A. van Hal, J. L. J. van Dongen and R. A. J. Janssen, Adv. Funct. Mater., 2001, 11, 255.

33 J. Cao, Q. Liao, X. Du, J. Chen, Z. Xiao, Q. Zuo and L. Ding, Energy Environ. Sci., 2013, 6, 3224.

34 Y. Dong, X. Hu, C. Duan, P. Liu, S. Liu, L. Lan, D. Chen, L. Ying, S. Su, X. Gong, F. Huang and Y. Cao, Adv. Mater., 2013, 25, 3683.

35 Z. Zhang, F. Lin, H.-C. Chen, H.-C. Wu, C.-L. Chung, C. Lu, S.-H. Liu, S.-H. Tung, W.-C. Chen, K.-T. Wong and P.-T. Chou, Energy Environ. Sci., 2015, 8, 552.

36 W. Yue, R. S. Ashraf, C. B. Nielsen, E. Collado-Fregoso, M. R. Niazi, S. A. Yousaf, M. Kirkus, H.-Y. Chen, A. Amassian, J. R. Durrant and I. McCulloch, Adv. Mater., 2015, 27, 4702 .
37 Y. Liang, D. Feng, Y. Wu, S.-T. Tsai, G. Li, C. Ray and L. Yu, J. Am. Chem. Soc., 2009, 131, 7792.

38 C. Cui, W.-Y. Wong and Y. Li, Energy Environ. Sci., 2014, 7, 2276.

39 J. Warnan, C. Cabanetos, R. Bude, A. El Labban, L. Li and P. M. Beaujuge, Chem. Mater., 2014, 26, 2829.

40 M. Zhang, X. Guo, W. Ma, H. Ade and J. Hou, Adv. Mater., 2014, 26, 5880.

41 C. B. Nielsen, R. S. Ashraf, N. D. Treat, B. C. Schroeder, J. E. Donaghey, A. J. P. White, N. Stingelin and I. McCulloch, Adv. Mater., 2015, 27, 948.

42 T. Lei, J.-Y. Wang and J. Pei, Chem. Mater., 2014, 26, 594.

43 J. Mei and Z. Bao, Chem. Mater., 2014, 26, 604.

44 Z.-G. Zhang and Y. Li, Sci. China: Chem., 2015, 58, 192.

45 E. G. Wang, M. Wang, L. Wang, C. H. Duan, J. Zhang, W. Z. Cai, C. He, H. B. Wu and Y. Cao, Macromolecules, 2009, 42, 4410.

46 A. T. Yiu, P. M. Beaujuge, O. P. Lee, C. H. Woo, M. F. Toney and J. M. J. Fréchet, J. Am. Chem. Soc., 2012, 134, 2180.

47 C. Duan, W. Cai, B. B. Y. Hsu, C. Zhong, K. Zhang, C. Liu, Z. $\mathrm{Hu}$, F. Huang, G. C. Bazan, A. J. Heeger and Y. Cao, Energy Environ. Sci., 2013, 6, 3022.

48 Y. Li, J. Zou, H.-L. Yip, C.-Z. Li, Y. Zhang, C.-C. Chueh, J. Intemann, Y. Xu, P.-W. Liang, Y. Chen and A. K. Y. Jen, Macromolecules, 2013, 46, 5497.

49 I. Meager, R. S. Ashraf, S. Mollinger, B. C. Schroeder, H. Bronstein, D. Beatrup, M. S. Vezie, T. Kirchartz, A. Salleo, J. Nelson and I. McCulloch, J. Am. Chem. Soc., 2013, 135, 11537.

50 C. Cabanetos, A. El Labban, J. A. Bartelt, J. D. Douglas, W. R. Mateker, J. M. J. Fréchet, M. D. McGehee and P. M. Beaujuge, J. Am. Chem. Soc., 2013, 135, 4656.

51 W.-H. Chang, J. Gao, L. Dou, C.-C. Chen, Y. Liu and Y. Yang, Adv. Energy Mater., 2014, 4, 1300864.

52 J. Gao, L. Dou, W. Chen, C.-C. Chen, X. Guo, J. You, B. Bob, W.-H. Chang, J. Strzalka, C. Wang, G. Li and Y. Yang, Adv. Energy Mater., 2014, 4, 1300739.

53 K. R. Graham, C. Cabanetos, J. P. Jahnke, M. N. Idso, A. El Labban, G. O. Ngongang Ndjawa, T. Heumueller, K. Vandewal, A. Salleo, B. F. Chmelka, A. Amassian, P. M. Beaujuge and M. D. McGehee, J. Am. Chem. Soc., 2014, 136, 9608.

54 I. Osaka, M. Saito, T. Koganezawa and K. Takimiya, Adv. Mater., 2014, 26, 331.

55 D. Dang, W. Chen, S. Himmelberger, Q. Tao, A. Lundin, R. Yang, W. Zhu, A. Salleo, C. Müller and E. Wang, Adv. Energy Mater., 2014, 4, 1400680.

56 N. Cho, C. W. Schlenker, K. M. Knesting, P. Koelsch, H.-L. Yip, D. S. Ginger and A. K. Y. Jen, Adv. Energy Mater., 2014, 4, 1301857.

57 S. Zhang, M. A. Uddin, W. Zhao, L. Ye, H. Y. Woo, D. Liu, B. Yang, H. Yao, Y. Cui and J. Hou, Polym. Chem., 2015, 6, 2752.

58 B. Meng, H. Song, X. Chen, Z. Xie, J. Liu and L. Wang, Macromolecules, 2015, 48, 4357.

59 C. Duan, A. Furlan, J. J. van Franeker, R. E. M. Willems, M. M. Wienk and R. A. J. Janssen, Adv. Mater., 2015, 27, 4461. 
60 J. Subbiah, B. Purushothaman, M. Chen, T. Qin, M. Gao, D. Vak, F. H. Scholes, X. Chen, S. E. Watkins, G. J. Wilson, A. B. Holmes, W. W. H. Wong and D. J. Jones, Adv. Mater., 2015, 27, 702.

61 Z. Xiao, K. Sun, J. Subbiah, T. Qin, S. Lu, B. Purushothaman, D. J. Jones, A. B. Holmes and W. W. H. Wong, Polym. Chem., 2015, 6, 2312.

62 W. Li, S. Albrecht, L. Yang, S. Roland, J. R. Tumbleston, T. McAfee, L. Yan, M. A. Kelly, H. Ade, D. Neher and W. You, J. Am. Chem. Soc., 2014, 136, 15566.

63 H. Wang, X. Yu, C. Yi, H. Ren, C. Liu, Y. Yang, S. Xiao, J. Zheng, A. Karim, S. Z. D. Cheng and X. Gong, J. Phys. Chem. C, 2013, 117, 4358.

64 X. He, S. Mukherjee, S. Watkins, M. Chen, T. Qin, L. Thomsen, H. Ade and C. R. McNeill, J. Phys. Chem. C, 2014, 118, 9918.

65 P. Liu, K. Zhang, F. Liu, Y. Jin, S. Liu, T. P. Russell, H.-L. Yip, F. Huang and Y. Cao, Chem. Mater., 2014, 26, 3009.

66 J. C. Bijleveld, A. P. Zoombelt, S. G. J. Mathijssen, M. M. Wienk, M. Turbiez, D. M. de Leeuw and R. A. J. Janssen, J. Am. Chem. Soc., 2009, 131, 16616.

67 L. Dou, J. You, J. Yang, C.-C. Chen, Y. He, S. Murase, T. Moriarty, K. Emery, G. Li and Y. Yang, Nat. Photonics, 2012, 6, 180.

68 L. J. A. Koster, V. D. Mihailetchi and P. W. M. Blom, Appl. Phys. Lett., 2006, 88, 093511.

69 C. H. Duan, C. D. Wang, S. J. Liu, F. Huang, C. H. W. Choy and Y. Cao, Sci. China: Chem., 2011, 54, 685.

70 J. Lee, M. Kim, B. Kang, S. B. Jo, H. G. Kim, J. Shin and K. Cho, Adv. Energy Mater., 2014, 4, 1400087.
71 Y. Yang, R. Wu, X. Wang, X. Xu, Z. Li, K. Li and Q. Peng, Chem. Commun., 2014, 50, 439.

72 C. G. Shuttle, R. Hamilton, B. C. O'Regan, J. Nelson and J. R. Durrant, Proc. Natl. Acad. Sci. U. S. A., 2010, 107, 16448.

73 D. J. Wehenkel, K. H. Hendriks, M. M. Wienk and R. A. J. Janssen, Org. Electron., 2012, 13, 3284.

74 L. J. A. Koster, M. Kemerink, M. M. Wienk, K. Maturová and R. A. J. Janssen, Adv. Mater., 2011, 23, 1670.

75 C. M. Proctor, M. Kuik and T.-Q. Nguyen, Prog. Polym. Sci., 2013, 38, 1941.

76 S. Kouijzer, J. J. Michels, M. van den Berg, V. S. Gevaerts, M. Turbiez, M. M. Wienk and R. A. J. Janssen, J. Am. Chem. Soc., 2013, 135, 12057.

77 J. J. van Franeker, M. Turbiez, W. Li, M. M. Wienk and R. A. J. Janssen, Nat. Commun., 2015, 6, 6229.

78 X. Zhang, H. Bronstein, A. J. Kronemeijer, J. Smith, Y. Kim, R. J. Kline, L. J. Richter, T. D. Anthopoulos, H. Sirringhaus, K. Song, M. Heeney, W. Zhang, I. McCulloch and D. M. DeLongchamp, Nat. Commun., 2013, 4, 2238.

79 R. Noriega, J. Rivnay, K. Vandewal, F. P. V. Koch, N. Stingelin, P. Smith, M. F. Toney and A. Salleo, Nat. Mater., 2013, 12, 1038.

80 R. C. Coffin, J. Peet, J. Rogers and G. C. Bazan, Nat. Chem., 2009, 1, 657.

81 W. Li, L. Yang, J. R. Tumbleston, L. Yan, H. Ade and W. You, Adv. Mater., 2014, 26, 4456.

82 K. Maturová, S. S. van Bavel, M. M. Wienk, R. A. J. Janssen and M. Kemerink, Nano Lett., 2009, 9, 3032.

83 N. E. Jackson, B. M. Savoie, T. J. Marks, L. X. Chen and M. A. Ratner, J. Phys. Chem. Lett., 2015, 6, 77. 